\title{
INFLUENCE OF CORROSION DAMAGE ON CYCLIC FATIGUE LIFE OF TEE WELDED JOINTS TREATED BY HIGH-FREQUENCY MECHANICAL PEENING
}

\author{
V.V. KNYSH, S.A. SOLOVEJ, L.I. NYRKOVA, L.G. SHITOVA and A.A. KADYSHEV \\ E.O. Paton Electric Welding Institute, NASU \\ 11 Kazimir Malevich Str., 03680, Kiev, Ukraine. E-mail: office@paton.kiev.ua
}

\begin{abstract}
We studied the effectiveness of application of high-frequency mechanical peening to improve fatigue resistance characteristics of tee welded joints in metal structures which are operated in a sea climate. Corrosion damage characteristic for such structures after long-term service was produced by soaking the welded joints in KST-1 salt spray chamber for 1200 h. Metallographic studies were conducted of weld zone and HAZ of welded joints in the initial (unstrengthened) state and in the state of strengthening by the HFMP technology after the impact of corrosive environment. It was established that strengthening by this technology does not improve the joint resistance to the impact of neutral salt spray. Fatigue testing of welded joints were performed in the initial and strengthened state after the impact of neutral salt spay. It was found that strengthening tee welded joints by HFMP before the corrosive impact allows increasing their fatigue strength at $2 \cdot 10^{6}$ cycles by $48 \%$ and increasing cyclic fatigue life by $2-5$ times. 19 Ref., 1 Table, 6 Figures.
\end{abstract}

Keywords: tee welded joint, neutral salt spray, fatigue, high-frequency mechanical peening, ultrasonic impact treatment, increase of corrosion fatigue resistance

Various treatments of surface layer of metals and alloys are widely used to improve their corrosion resistance, promoting a change of their structure, hardness improvement, relieving tensile residual stresses and inducing compressive residual stresses, as well as reducing stress concentration. Papers of recent years on this subject are devoted both to studying the technological features of surface strengthening by traditional methods of plastic deformation of metal (for instance, shot blasting), and to investigation of new treatments [1-5]. Compared to such costly and unproductive treatments as surface melting by nanopulsed laser [3] or high-power pulsed electron beam [4], steel ball attrition treatment with vacuum chamber application [5], swaging in the hot or cold state [6-8], application of high-frequency mechanical peening $[9,10]$ has a number of advantages.

Compactness, mobility and low cost of equipment for high-frequency mechanical peening (HFMP) allows strengthening parts of machines and metal structures in any spatial position in the field, in particular under the water [11]. Works [12-15] give the results of experimental studies of the effectiveness of application of HFMP technology, known in foreign publications as «ultrasonic shock treatment», to improve corrosion resistance and characteristics of corrosion fatigue resistance of welded joints. In these studies assessment of corrosion resistance, corrosion rate and corrosion fatigue of welded joints was performed in $\mathrm{NaCl}$ solutions.
Analysis of polarization fatigue curves showed that strengthening by HFMP technology increases the corrosion potential and lowers the corrosion rate of peening zone (line of weld metal transition to HAZ). Here, cyclic fatigue life of butt welded joints of pipes rises 2 times, and that of tee joints - up to 6 times. It should be noted that the above data of accelerated corrosion testing do not give an idea about lowering of service properties of HFMP-treated welded joints as the strengthened metal layer is destroyed.

Influence of partial corrosion loss of HFMP-strengthened metal layer on residual stress fields and cyclic fatigue life of welded joints is considered in [16, 17]. In [16] it is shown that corrosion damage of welded joints of low-alloyed shipbuilding steel equivalent to 7.5 years of operation leads to reduction of the thickness of surface layer of metal with induced residual compressive stresses approximately from 1.5 to $1.0 \mathrm{~mm}$, and lowering of their maximum level. The authors came to the conclusion about the rationality of welded joint treatment by HFMP, as compressive residual stresses are induced in the peening zone instead of tensile residual stresses, and they are preserved even at partial loss of the strengthened layer. In [17] metallographic studies showed that soaking of welded joints of weather-resistant steel in moisture chamber G4 at elevated temperature and moisture for $1200 \mathrm{~h}$ leads to partial damage of the strengthened metal layer as a result of formation of corrosion cavi- 
ties. Experimental data, obtained on tee welded joints after corrosion impact, show that pre-strengthening by HFMP improves the fatigue strength at $2 \cdot 10^{6}$ cycles of such joints by approximately $48 \%$, and their cyclic fatigue life rises 6 to 8 times. Unlike low-alloyed steels, soaking of stainless steel samples in aggressive media for $1000 \mathrm{~h}$ does not lead to a significant damage of strengthened metal layer $[18,19]$.

Thus, results of studies [16-19] show that establishing the characteristics of fatigue resistance of welded joints at considerable damage (corrosion loss) of HFMP-strengthened layer of metal is an urgent task. Significant corrosion damage can be produced by prior soaking of welded joints in salt spray chamber, which allows simulation of metal structure operation in sea climate.

The objective of this work is assessment of fatigue resistance characteristics of tee welded joints strengthened by HFMP after soaking in neutral salt spray environment.

Material and investigation procedure. Experimental studies for corrosion fatigue were conducted on samples of tee welded joints of low-alloyed steel $15 \mathrm{KhSND}\left(\sigma_{\mathrm{y}}=400 \mathrm{MPa}, \sigma_{\mathrm{t}}=565 \mathrm{MPa}\right)$, which is extensively applied for fabrication of elements of metal structures for long-term operation (for instance, in superstructures of railway and road bridges), has higher strength, good weldability, is resistant to atmospheric conditions and operative in the temperature range from -70 up to $45^{\circ} \mathrm{C}$.

Blanks for welded joint samples were cut out of hot-rolled sheet of $12 \mathrm{~mm}$ thickness, category 12. Dimensions of blanks for tee joints were $350 \times 70 \mathrm{~mm}$. Tee joints were produced by welding on transverse stiffeners (also from 15KhSND steel) by manual arc process with electrodes of UONI 13/55 grade by fillet welds from two sides of the plate. Root weld (first layer) was made with $3 \mathrm{~mm}$ diameter electrodes, and face weld (second layer) - with $4 \mathrm{~mm}$ electrodes. Shape and geometrical dimensions of samples of tee welded joints are given in Figure 1. Sample thickness is due to wide applicability of $12 \mathrm{~mm}$ rolled stock in engineering welded metal structures, and working part width of $50 \mathrm{~mm}$ was selected, proceeding from test equipment capacity.

Experimental studies were conducted in servohydraulic machine URS-20 at alternating tension with cycle asymmetry $R_{\sigma}=0$ and frequency of $5 \mathrm{~Hz}$ at regular loading. Criterion of test completion was complete failure of samples or exceeding test base of $2 \cdot 10^{6}$ cycles of stress reversal. Samples were tested in the initial state and in HFMP-strengthened state after soaking in corrosive medium.

Welded joint strengthening by HFMP technology was performed with USTREAT-1.0 equipment,
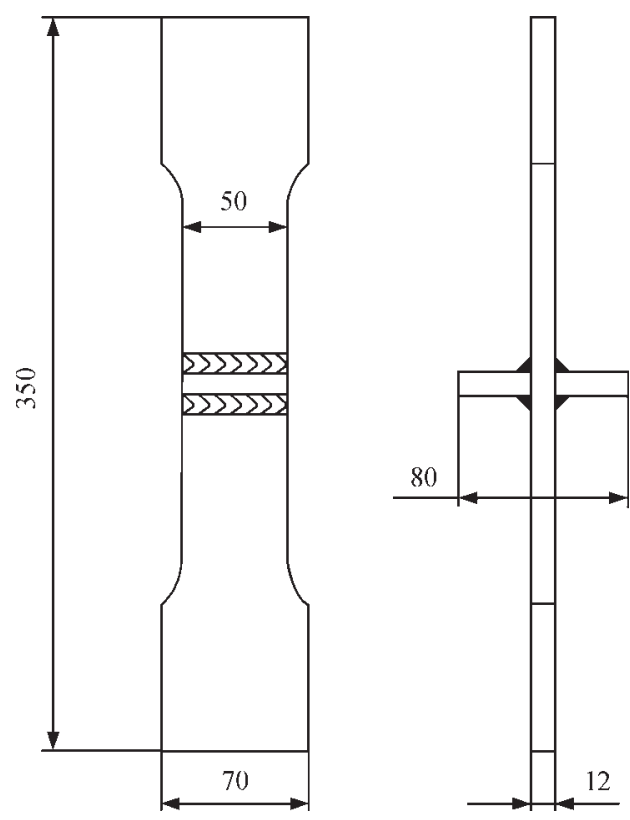

Figure 1. Shape and dimensions of tee welded joint samples

in which manual compact impact tool with piezoceramic converter is connected to ultrasonic generator of $500 \mathrm{~W}$ power. At strengthening of welded joints by HFMP, surface plastic deformation was applied to a narrow zone of weld metal transition to HAZ (along the fusion line). Single-row four-striker attachment with striker diameter of $3 \mathrm{~mm}$ was used as the strengthening tool. Speed of HFMP performance in treatment of tee welded joints was equal to $1 \mathrm{~mm} / \mathrm{s}$, and amplitude of oscillations of the end of waveguide of manual impact tool was $25 \mu \mathrm{m}$.

To produce preliminary corrosion damage welded samples were placed into KST-1 salt spray chamber. Investigations were conducted to GOST 9.401-91 «USCAP. Paint coatings. General requirements and methods of accelerated tests on resistance to the action of climatic factors (method 1, B)» in KST-1 at temperature of $(35 \pm 2)^{\circ} \mathrm{C}$ with spraying of sodium chloride solution for 15 min every 45 min of studies. Sodium chloride concentration in the solution was $(50 \pm 5) \mathrm{g} / \mathrm{dm}^{3}$, $\mathrm{pH}$ was from 6.5 to 7.2 , and density was $1.03 \mathrm{~g} / \mathrm{cm}^{3}$. Conductivity of distilled water for preparation of sodium chloride solution is not more than $20 \mu \mathrm{Ohm} / \mathrm{cm}$ at temperature of $(25 \pm 2)^{\circ} \mathrm{C}$. Duration of welded sample staying under the impact of salt spray was $1200 \mathrm{~h}$.

Metallographic studies of surface layer of weld metal and HAZ of tee welded joints after soaking in KST-1 salt spray chamber were conducted on samples in the initial (unstrengthened) state and in HFMP-strengthened state. Results of metallographic studies of the surface layer of the metal of weld and HAZ of similar welded joints in the initial and HFMP-strengthened states prior to corrosion impact are given in [17]. 


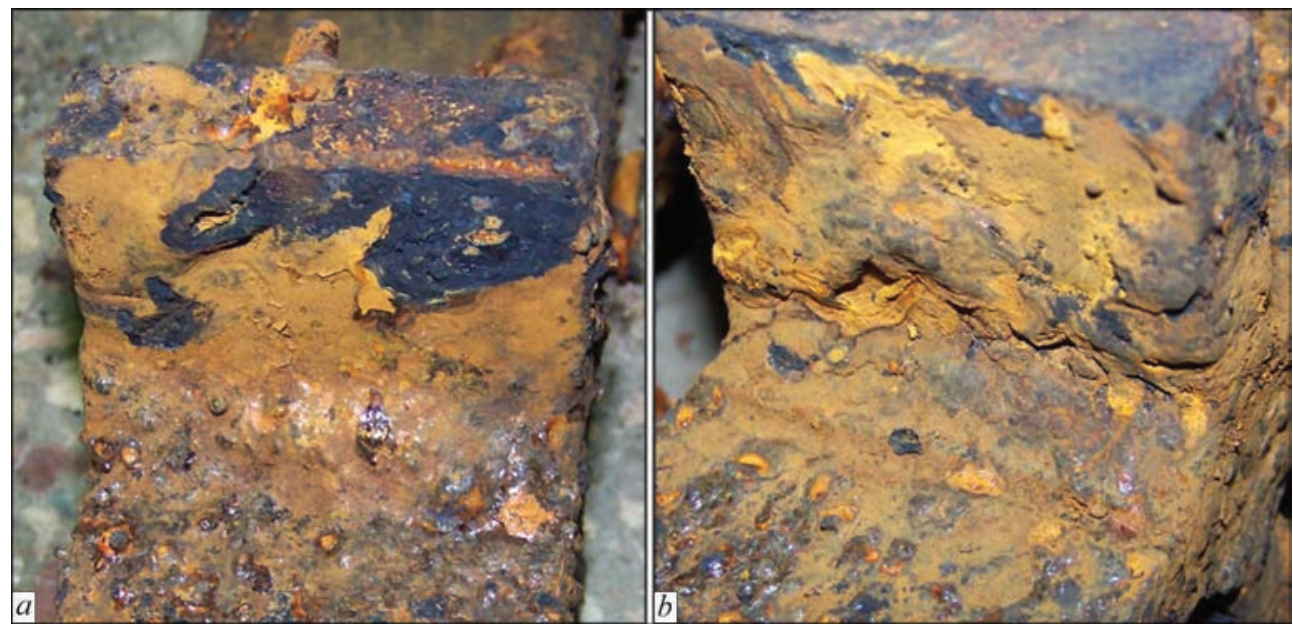

Figure 2. Appearance of weld zone of tee welded joint in the initial ( $a$ ) and HFMP-strengthened $(b)$ states after exposure to neutral salt spray for $1200 \mathrm{~h}$

Investigation results. After soaking in salt spray chamber for $1200 \mathrm{~h}$ the samples were coated by the layer of corrosion products of up to 1-2 $\mathrm{mm}$ (Figure 2). In surface layers of weld metal of tee welded joint in unstrengthened state after soaking in chamber quite extended corrosion damage is observed in the form of spots and cavities of $1.95 \times 0.65,4.16 \times 0.26$, $2.73 \times 0.195 \mathrm{~mm}$ size. In HAZ metal corrosion damage is less extended, but deeper, of up to $0.56 \times 0.52$ and $1.30 \times 0.65 \mathrm{~mm}$ size. Corrosion damage in the HAZ surface layers is located predominantly along the fusion boundary of coarse grain zone, and in some cases they cavities are filled with corrosion products (Figure 3).

After HFMP strengthening plastically deformed layers of weld metal $1.70-1.82 \mathrm{~mm}$ wide and of HAZ metal 1.3-1.7 mm wide formed under the groove. Here their depth, due to visible changes of metal structure

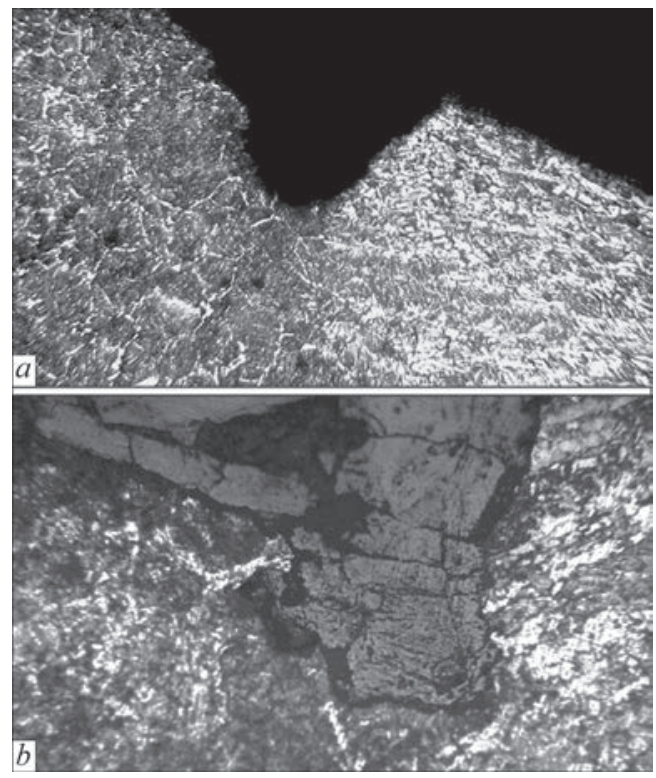

Figure 3. Corrosion cavities in surface layer of metal of coarse grain zone in tee welded joint after exposure to neutral salt spray for $1200 \mathrm{~h}: a-\times 100 ; b-\times 250$ under the groove, was equal to $390-650 \mu \mathrm{m}$, before placing into chamber. After soaking tee welded joint samples in chamber, the width of strengthened metal layer decreased to $0.52-1.30 \mathrm{~mm}$, and its depth — to 65-455 $\mu \mathrm{m}$. Individual regions showed just traces of HFMP-strengthened metal layer $0.52 \mathrm{~mm}$ wide and 65-91 $\mu \mathrm{m}$ deep, located either in weld metal or in HAZ metal, that is indicative of practically complete damage (loss) of the strengthened layer.

In strengthened surface layers of metal of fillet welds and HAZ of welded joints after soaking in chamber, cavities of $2.60 \times 0.26,2.08 \times 0.65 \mathrm{~mm}$ in the weld metal and of $1.69 \times 0.65$ and $0.36 \times 0.78 \mathrm{~mm}$ size in the HAZ metal were found along the fusion boundary. Characteristic corrosion damage of strengthened surface layer of metal is as follows: spot corrosion with different penetration depth (Figure 4,a); surface corrosion to the depth from 0.02 to $0.13 \mathrm{~mm}$ (Figure $4, b$ ); complex corrosion damage, which are cavities, developing into pitting, and corrosion cracks, developing into cavities, filled with corrosion products (Figure 4, c).

Results of metallographic investigations with computed values of the extent of damage and total projected damage surface area, depth of corrosion spot and cavity penetration into the surface layers of metal of fillet welds and HAZ in tee welded joints are given in the Table. Depth of penetration of corrosion spots in the surface layer of metal of the weld and HAZ for welded joints in the initial and HFMP-strengthened states is practically the same and is equal to 0.65 and $0.78 \mathrm{~mm}$, respectively. Thus, strengthening by HFMP technology does not improve the corrosion resistance of samples of tee welded joints under the conditions of exposure to neutral salt spray.

Results of fatigue testing of samples of tee welded joint of $15 \mathrm{KhSND}$ steel after soaking in salt spray chamber are shown in Figure 5. Experimental data 


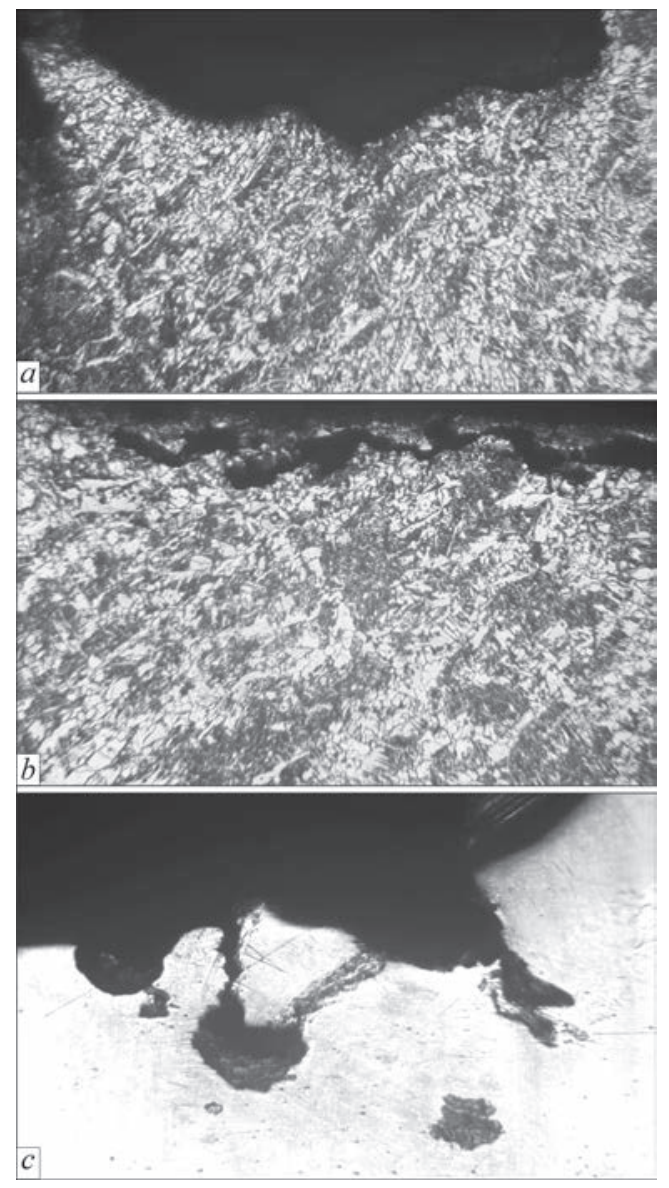

Figure 4. Corrosion damage of HFMP-strengthened surface layer of metal of tee welded joint after exposure to neutral salt spray for $1200 \mathrm{~h}(a, b-\times 110 ; c-\times 250)$

obtained in [17] on identical welded joints without corrosion damage are also given there.

Soaking of samples of tee welded joints in salt spray chamber for $1200 \mathrm{~h}$ leads to lowering of fatigue strength at $2 \cdot 10^{6}$ cycles in unstrengthened welded joints by $25 \%$ (from 180 to $135 \mathrm{MPa}$ ), and in HFMP-strengthened joints - by approximately $24.5 \%$ (from 265 to $200 \mathrm{MPa}$ ).

Application of HFMP as a method of surface plastic deformation of the joint metal near the points of fatigue damage localizing improves fatigue resistance characteristics of tee welded joints, both in air and at exposure to corrosive environment. Results obtained in welded joints after corrosive impact (see curves 2 and 4 in Figure 5) show that pre-strengthening by

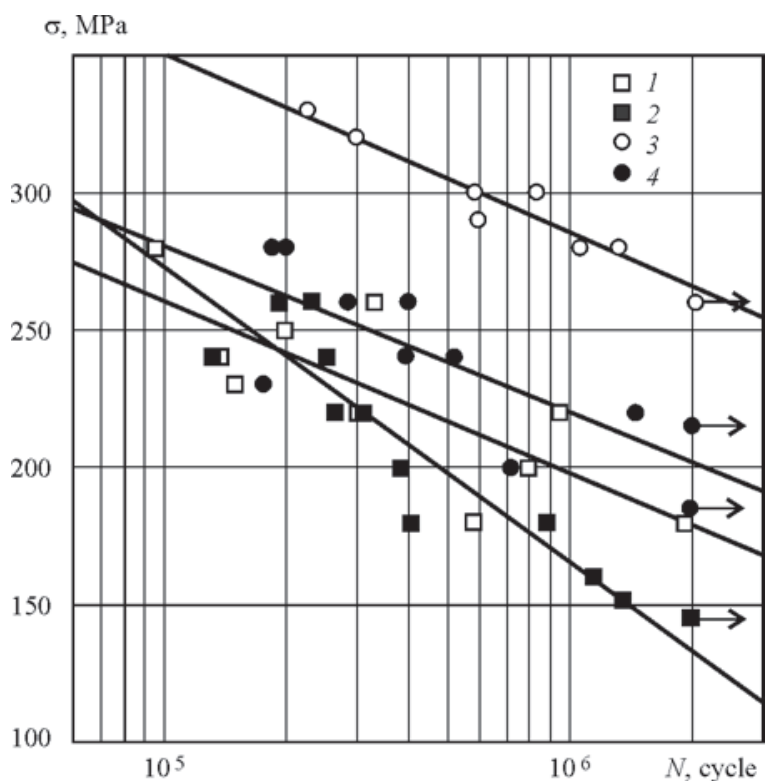

Figure 5. Fatigue curves of tee welded joints of 15KhSND steel: 1, 3 - in initial and HFMP-strengthened states in air [17]; 2, 4 the same after exposure to neutral salt spray for $1200 \mathrm{~h}$, respectively

HFMP technology increases the fatigue strength at $2 \cdot 10^{6}$ cycles of such joints by approximately $48 \%$ (from 135 up to $200 \mathrm{MPa}$ ), and improves cyclic fatigue life 2-5 times. It should be also noted that fracture of unstrengthened welded joints after soaking in chamber occurred along the line of weld metal transition to HAZ metal (Figure 6,a), and that of strengthened ones took place at a distance from the weld and HAZ, predominantly near the grip part (Figure 6,b). Such fracture is indicative of comparability of fatigue resistance characteristics of HFMP-strengthened welded joint and base metal with corrosion damage.

Thus, experimental results are indicative of the rationality of application of HFMP technology to improve fatigue resistance characteristics of tee welded joints of metal structures, exposed to alternating loading and sea climate in operation (see curves 2 and 4 in Figure 5). Despite corrosion loss of the main part of strengthened layer, fracture of welded joints runs through the base metal from surface corrosion damage. Here, it should be noted that protection of HFMP-strengthened surface layer of metal from direct impact of aggressive media, and from corrosion

Dimensions of corrosion damage in surface layers of metal of welds and HAZ in tee welded joints of $15 \mathrm{KhSND}$ steel after soaking for $1200 \mathrm{~h}$ in salt spray chamber

\begin{tabular}{|l|c|c|c|c|c|c|}
\hline \multirow{2}{*}{ Sample state } & \multicolumn{2}{|c|}{ Spot corrosion of surface layers of weld metal } & \multicolumn{2}{c|}{ Spot corrosion of surface layers of HAZ metal } \\
\cline { 2 - 7 } & $\begin{array}{c}\text { Damage } \\
\text { extent, \% }\end{array}$ & $\begin{array}{c}\text { Damage } \\
\text { depth, } \mathrm{mm}\end{array}$ & $\begin{array}{c}\text { Total projected } \\
\text { damage area, } \mathrm{mm}\end{array}$ & $\begin{array}{c}\text { Damage } \\
\text { extent, \% }\end{array}$ & $\begin{array}{c}\text { Damage } \\
\text { depth, mm }\end{array}$ & $\begin{array}{c}\text { Total projected } \\
\text { damage area, mm }\end{array}$ \\
\hline Unstrengthened & 50.4 & $0.039-0.65$ & 26.52 & 64 & $0.065-0.65$ & 9.78 \\
\hline HFMP-strengthened & 72 & $0.075-0.65$ & 40.10 & 62.5 & $0.065-0.78$ & 10 \\
\hline
\end{tabular}



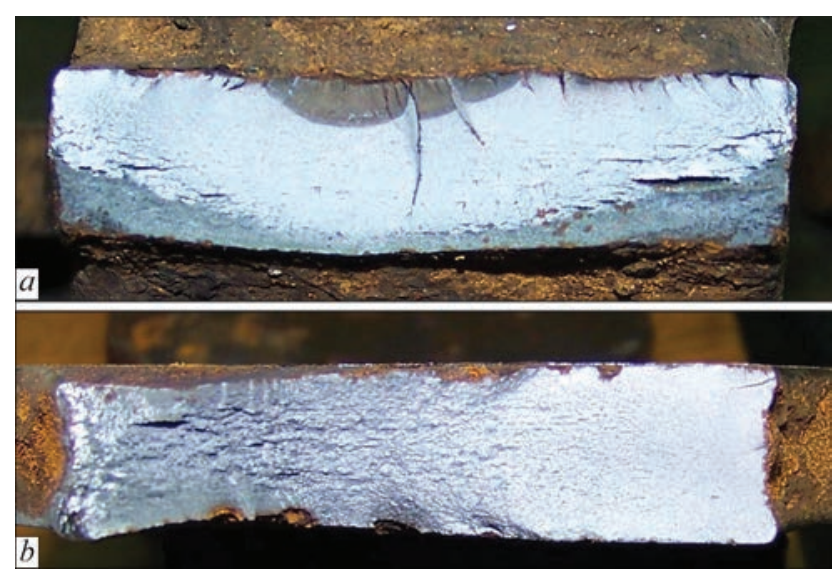

Figure 6. General view of fracture surface of tee welded joints in the initial (a) and HFMP-strengthened (b) states after corrosive impact and fatigue testing

damage, accordingly (for instance, by application of lacquer-paint coatings), allows achieving maximum characteristics of joint fatigue resistance (curve 1, Figure 5).

\section{Conclusions}

1. The paper gives the results of metallographic assessment of surface layers of metal of the weld and HAZ of welded joints in the initial (unstrengthened) and HFMP-strengthened state after exposure to neutral salt spray. It is found that strengthening by HFMP does not lead to improvement of joint resistance to the impact of neutral salt spray.

2. The high effectiveness of HFMP technology application to improve the fatigue resistance characteristics of welded joints in metal structures, operating in sea climate, was established. HFMP strengthening of tee welded joints of $15 \mathrm{KhSND}$ steel before soaking in neutral salt spray chamber for $1200 \mathrm{~h}$ leads to improvement of cyclic fatigue life $2-5$ times, depending on the levels of applied stresses, and to $48 \%$ increase of fatigue strength at $2 \cdot 10^{6}$ cycles.

3. It is shown that fracture of unstrengthened welded joints after soaking in salt spray chamber proceeds along the line of transition of weld metal to HAZ metal, and in HFMP-strengthened joints it occurs at a distance from the weld and HAZ, predominantly near the grip part (in base metal). Such a fracture is indicative of comparability of fatigue resistance characteristics of HFMP-strengthened welded joint and base metal with corrosion damage.

1. Ahmed, A.A., Mhaede, M., Basta, M. et al. (2015) Effect of shot peening parameters and hydroxyapatite coating on surface properties and corrosion behavior of medical grade AISI 316L stainless steel. Surface \& Coating Techn., 280, 347-358.

2. Zhiming, L., Laimin, S., Shenjin, Z. et al. (2015) Effect of high energy shot peening pressure on the stress corrosion cracking of the weld joint of 304 austenitic stainless steel. Materials Sci. and Eng. A, 637, 170-174.

3. Pacquentin, W., Caron, N., Oltra, R. (2015) Effect of microstructure and chemical composition on localized corrosion resistance of a AISI 304L stainless steel after nanopulsed-laser surface melting. Appl. Surface Sci., 356, 561-573.

4. Hao, S., Zhao, L., Zhang, Y. et al. (2015) Improving corrosion and wear resistance of FV520B steel by high current pulsed electron beam surface treatment. Nuclear Instruments and Methods in Physics Research B: Beam Interactions with Materials and Atoms, 356-357, 12-16.

5. Balusamy, T., Sankara Narayanan, T.S.N., Ravichandran, K. et al. (2013) Influence of surface mechanical attrition treatment (SMAT) on the corrosion behavior of AISI 304 stainless steel. Corrosion Sci., 74, 332-344.

6. Arifvianto, B., Widodo, T.D. (2015) Effect of cold working and sandblasting on the microhardness, tensile strength and corrosion resistance of AISI 316L stainless steel. Int. J. Minerals, Metallurgy and Materials, 19, 1093-1099.

7. Ahmed, A.A., Mhaede, M., Wollmann, M. et al. (2014) Effect of surface and bulk plastic deformations on the corrosion resistance and corrosion fatigue performance of AISI $316 \mathrm{~L}$. Surface \& Coating Techn., 259, 448-455.

8. Pokhmursky, V.I., Khoma, M.S. (2008) Corrosion fatigue of metals and alloys. Lviv: Spolom.

9. Lobanov, L.M., Kirian, V.I., Knysh, V.V. et al. (2006) Improvement of fatigue resistance of welded joints in metal structures by high-frequency mechanical peening (Review). The Paton Welding J., 9, 2-8.

10. Malaki, M., Ding, H. (2015) A review of ultrasonic peening treatment. Materials and Design, 87, 1072-1086.

11. Gao, W., Wang, D., Cheng, F. et al. (2015) Enhancement of the fatigue strength of underwater wet welds by grinding and ultrasonic impact treatment. J. Materials Proc. Techn., 223, 305-312.

12. Abdulah, A., Malaki, M., Eskandari, A. (2012) Strength enhancement of the welded structures by ultrasonic peening. Materials \& Design, 38, 7-18.

13. Prokopenko, G.I., Mordyuk, B.N., Knysh, V.V. et al. (2014) Improvement of fatigue strength and corrosion resistance of welded joints by ultrasonic impact peening and electrical-discharge alloying. Tekhn. Diagnostika i Nerazrush. Kontrol, 3, 34- 40.

14. Daavary, M., Sadough Vanini, S.A. (2015) Corrosion fatigue enhancement of welded steel pipes by ultrasonic impact treatment. Materials Let., 139, 462-466.

15. Daavary, M., Sadough Vanini, S.A. (2015) The effect of ultrasonic peening on service life of the butt-welded high-temperature steel pipes. J. Materials Eng. and Performance, 24, 3658-3665.

16. Ahmad, D., Fitzpatrick, M.E. (2015) Effect of ultrasonic peening and accelerated corrosion exposure on residual stress distribution in welded marine steel. Metallurg. and Materials Transact. A, 46, 1214-1226.

17. Knysh, V.V., Solovej, S.A., Nyrkova, L.I. et al. (2016) Improvement of cyclic fatigue life of tee welded joints by high-frequency mechanical peening under the conditions of higher humidity and temperature. The Paton Welding J., 3, 12-17.

18. Dong, Z., Liu, Z., Li, M. et al. (2015) Effect of ultrasonic impact peening on the corrosion of ferritic-martensitic steels in supercritical water. J. Nuclear Materials, 457, 266-272.

19. Nasilowska, B., Bogdanowicz, Z., Wojucki, M. (2015) Shot peening effect on $904 \mathrm{~L}$ welds corrosion resistance J. Construct. Steel Res., 115, 276-282. 